\title{
Alarming development of dual snus and cigarette usage among young Finnish males
}

\author{
Maria Danielsson ${ }^{1,2^{*}}$ (D) Anelma Lammi ${ }^{3}$, Simo Siitonen ${ }^{1}$, Jukka Ollgren ${ }^{4}$, Liisa Pylkkänen ${ }^{5,6}$ and Tuula Vasankari, ${ }^{3,7}$
}

\begin{abstract}
Background: The consumption of tobacco products has evolved to include more complex combinations of different products. We investigated the tobacco habits of a representative population of young Finnish male conscripts in order to evaluate the prevalence of dual use of cigarettes and snus as well as the transition from one tobacco product to another. In addition, we evaluated the correlation between the level of education and the use of cigarettes and snus.

Methods: A questionnaire-based survey was carried out in three out of 17 garrisons among conscripts during their first week of service in 2014. A total of 1971 male conscripts were selected by simple random sampling of the 9013 males in the selected garrisons. Of them 1916 participated and filled in the questionnaire. The response rate was 97.2\%. The questionnaire consisted of 25 questions including age, gender, basic education, use of tobacco products as well as questions assessing nicotine dependency.

Results: The amount of dual users of cigarettes and snus was $21 \%$. There was a higher probability of dual use of cigarettes and snus among smokers compared to snus users $(p<0.001)$. One third (35\%) of former smokers reported daily snus use and over $40 \%$ of the former snus users smoked daily. One third (34\%) of the participants reported snus usage and $14 \%$ of the study subjects used snus daily. $40 \%$ of the study population were smokers and over $25 \%$ smoked daily. Of the participants with basic educational background 57\% smoked daily $(p<0.001)$, however, no association between snus and level of education was found $(p=0.69)$.

Conclusions: This study provides better understanding of the complex tobacco habits of young adult males. The simultaneous usage of multiple tobacco products as well as the high tendency to transition from one tobacco product to another should be taken into consideration when planning cessation interventions in health care settings and tobacco control policies at societal levels.
\end{abstract}

Keywords: Tobacco, Cigarettes, Smokeless tobacco, Snus, Dual use, Transition, Education

\section{Key points}

- Exclusive snus use as well as dual use of cigarette and snus were significantly higher than expected.

- Smoking correlated with low educational level, but this could not be shown among snus users.

- The notably high prevalence of snus usage seems to reflect the emerging change of trend among tobacco consumers.

\footnotetext{
* Correspondence: maria.danielsson@helsinki.fi; maria.danielsson@mil.fi ${ }^{1}$ The Finnish Defence Forces, Fabianinkatu 2, 00130 Helsinki, Finland 2Doctoral School in Health Sciences, University of Helsinki, P.O. BOX 3, 00014 Helsinki, Finland

Full list of author information is available at the end of the article
}

\section{Background}

A significant decline in smoking, especially among welleducated individuals can be seen worldwide in developed countries [1-3]. However, there are signs that the use of non-cigarette tobacco products has increased despite tobacco control programs, restriction on marketing of tobacco products and the ban on trade of smokeless tobacco in Australia, Israel and the European Union, excluding Sweden [3, 4]. The consumption of tobacco products has evolved to include more complex tobacco habits and the dual use of different tobacco products, mainly cigarettes and smokeless tobacco, has become common [5-11].

(c) The Author(s). 2019 Open Access This article is distributed under the terms of the Creative Commons Attribution 4.0 International License (http://creativecommons.org/licenses/by/4.0/), which permits unrestricted use, distribution, and 
The transition from the Swedish type low- nitrosamine smokeless tobacco (snus) to cigarettes and vice versa has mainly been studied in Sweden. According to Galanti et al. (2008), who analyzed several studies from Sweden, Finland and North America, current snus use was mainly associated with non-smokers or former smokers. Smoking induction or the gateway theory only seemed to affected a minority [12]. However, Furberg et al. (2006) discovered that the transition from cigarettes to snus use among males is often incomplete resulting in dual usage [13]. Some research suggests that smokeless tobacco might actually initiate smoking [14-16].

Snus is most commonly used in Scandinavia and the United States, prominently in Sweden and Norway, where smokeless tobacco trade is legal $[17,18]$. A study Hamari et al. (2013) carried out on military recruits in Northern Finland indicated that almost half of daily snus users also smoked [8]. In Sweden, Norway and in the United States dual usage is relatively uncommon, but the pattern is more frequent among young adults and adolescents [7, 19, 20]. Recent studies also show increased awareness, openness and readiness for consuming non-cigarette tobacco products [11, 20-25].

Snus is perceived as a less harmful product than cigarettes and even as a means of harm reduction [26, 27], but the absorption through the mucous membrane is effective and results in a high dose of nicotine intake. In addition, snus contains a high amount of nicotine, around 20 carcinogens and over 2500 chemicals [17, 28].

The correlation between disadvantaged socioeconomic and socio-educational status and smoking is well acknowledged [29-32]. This seems to apply to the transition from sporadic use to daily use as well [33]. However, knowledge about the correlations between snus use and socio-educational status is limited. Some studies suggest that use of snus is more often related to favorable social and health profiles than daily smoking [19, 31].

As discussed above, recent developments point towards a transition from exclusive smoking to usage of other tobacco products and complex tobacco habits. We therefore evaluated the prevalence of dual use of cigarettes and snus as well as the transition from one tobacco product to another by reported quitters, among a representative population of young Finnish males entering military service. In addition, we examined the overall prevalence of cigarette and snus usage and the correlation between the educational background of the participants and their smoking habits.

\section{Methods}

\section{Study population}

All Finnish males must attend a call-up for military service the year they turn 18 years of age and attend service before the age of 30 . Some conscripts may be excluded from military service due to medical or unsuitability factors or they may choose to do non-military service [3436]. Approximately $77 \%$ of men from the age group attend military service, while about $2 \%$ of females voluntarily choose to do so $[37,38]$.

\section{Sampling}

Three out of 17 Finnish garrisons, The Guard Jaeger Regiment, the Karelian Brigade and the Kainuu Brigade were chosen as they train recruits coming from different parts of Finland. The troops were selected by simple random sampling.

This study covered both cohorts entering military service in January and June 2014. Altogether 9013 males of those 24,752 Finnish males attending military service during the study year started their service in the selected three garrisons, from which we by simple random sampling chose a representative sample of 1971 male conscripts of which 1916 participated and filled in the questionnaire. The response rate was high, 97.2\%. Figure 1.

The material reflects the tobacco habits of young adult Finnish males. Females were excluded from this analysis because only $2.7 \% \quad(n=53)$ of the respondents were women and could not be considered to represent the use of tobacco products of Finnish young women in general.

\section{Data collection and measurement}

The questionnaire-based survey was carried out concurrently with the general health inspection during the first week of service. The questionnaire developed for this study consisted of 25 questions including age, gender, basic education, use of tobacco products including tobacco and snus as well as questions assessing nicotine dependency. The use of electric cigarettes was included in the questionnaire but was excluded from the analysis due to very low usage (1.4\%). Additional file 1

Tobacco users were grouped according to their tobacco habits. The three main categories were smokers, snus users and non-users. Self-rolled tobacco was combined with manufactured tobacco due to the very low number of self-rolled users. These groups were subdivided into daily users, occasional users, quitters and dual users of cigarettes and snus. The 'never'-group was defined by the statement "I have never smoked or used snus on a daily basis". Questions concerning smoking and snus use were formulated as recommended by WHO and validated in several earlier studies [39].

The dual use of cigarettes and snus was determined by the simultaneous daily and/or occasional use of both products. The habit of consumption was not specified. Transition from one product to another was calculated by comparing current smokers/snus users to current quitters.

The educational level was subdivided into the following three categories: basic education (consisting of 9 


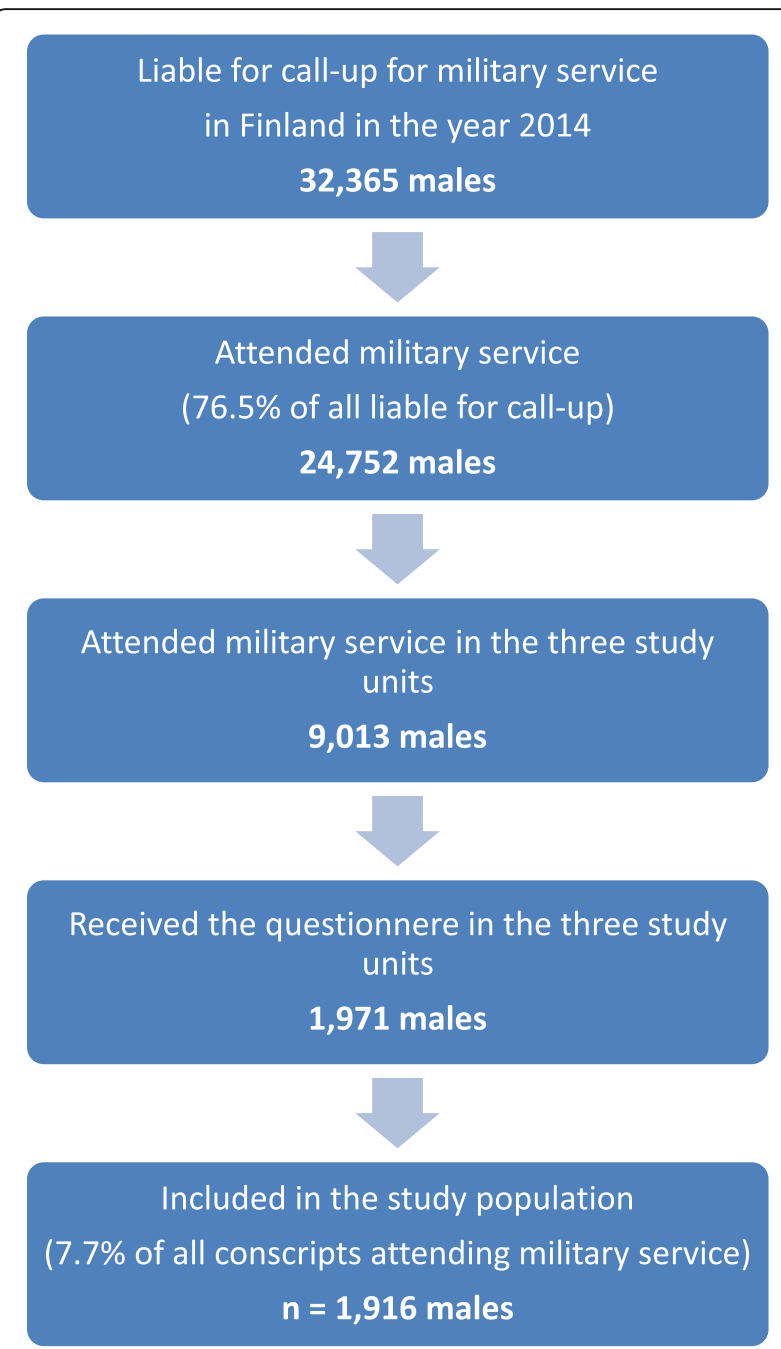

Fig. 1 Flowchart showing the data selection of the study population in the year 2014

years of compulsory education), vocational school and upper secondary school.

\section{Statistical analysis}

The data was analyzed by using the IBM SPSS Statistics software package, version 23. The Chi-Square Test of independence was used to assess if there is a relationship between two categorical variables. Trends in a largerthan $-2 \times 2$ table with ordinal level categorical variables were tested with the Mantel-Haenszel test of trend (the linear-by-linear association test). The equality between the table row marginal proportions and the corresponding table column proportions (marginal homogeneity) were tested by the marginal homogeneity test. [40-42]

\section{Ethical approval}

The study was approved by the Ethical Committee of Helsinki and Uusimaa Hospital District, Finland. All participants gave their written informed consent. The subjects were informed about the use of the collected data for research purposes, and consented to participate on a voluntary basis in compliance with the principles of the WMA Declaration of Helsinki.

\section{Results}

The mean age of the study population of 1916 male conscripts was 19.4 years $( \pm$ SD 1.1 years $)$ with a range of $18-28$ years. A majority, $92 \%$ of the study subjects, were $18-20$ years. Half (51\%) of the respondents had attended upper secondary school, $38 \%$ had a vocational education background and $10 \%$ had only basic education prior to conscription. Table 1.

\section{Use of any tobacco products}

Almost $40 \%$ of these conscripts were smokers, either daily or occasionally, and of them $66 \%$ smoked every day. Respectively, every third young male (34\%) used snus and $42 \%$ of them used it daily. Table 2 .

Our findings showed a strong linear association between the educational background of the participants and their smoking habits $(p<0.001)$. Only $10 \%$ of the subjects with an upper secondary educational background smoked daily, while $57 \%$ of those with a basic education smoked every day. However, we could not find a statistically significant correlation between educational level and exclusive snus use $(p=0.690)$. Table 1 .

\section{Dual use of tobacco products}

In our study, up to $21 \%$ of all conscripts reported dual tobacco consumption and over $2 \%$ reported daily use. $9 \%$ of the daily smokers used snus every day and $41 \%$ occasionally. Respectively, $17 \%$ of daily snus users smoked daily and $28 \%$ occasionally. Table 2 .

The dual use of cigarettes and snus had a linear association and are hence not independent factors (linear-bylinear test, $p<0.001)$. There was a higher probability of dual use of cigarettes and snus among smokers compared to snus users. Table 2.

Table 1 Daily use of cigarettes, snus and dual use of both products according to educational status $(n=1911)$ among the study population of Finnish male conscripts in 2014

\begin{tabular}{llll}
\hline & Daily smokers & $\begin{array}{l}\text { Daily snus } \\
\text { users }^{2}\end{array}$ & Daily dual use \\
\hline Basic education & $113(56.8 \%)$ & $27(13.6 \%)$ & $10(5 \%)$ \\
Vocational school & $282(38.8 \%)$ & $108(15.0 \%)$ & $22(3 \%)$ \\
Upper secondary school & $96(9.9 \%)$ & $132(13.6 \%)$ & $12(1.2 \%)$ \\
All & $491(25.9 \%)$ & $267(14.2 \%)$ & $44(2.3 \%)$ \\
\hline
\end{tabular}

Linear-by-linear association test for the trend: ${ }^{1} p<0.001,{ }^{2} p=0.690$ 
Table 2 Smoking, use of snus and dual use of cigarettes and snus among Finnish male conscripts in 2014 ( $N=1916)$

\begin{tabular}{|c|c|c|c|c|c|}
\hline Tobacco usage & Daily snus user & Occasional snus user & Former snus user & No snus use & Total \\
\hline Daily smoker & $45(2.4 \%)$ & $201(10.6 \%)$ & $52(2.8 \%)$ & $191(10.1 \%)$ & $489(25.8 \%)$ \\
\hline Occasional smoker & 74 (3.9\%) & $82(4.3 \%)$ & $16(0.9 \%)$ & $80(4.2 \%)$ & $252(13.3 \%)$ \\
\hline Former smoker & $56(3.0 \%)$ & $20(1.1 \%)$ & $31(1.6 \%)$ & $51(2.7 \%)$ & $158(8.4 \%)$ \\
\hline Non-smoker & $92(4.9 \%)$ & $64(3.4 \%)$ & $22(1.2 \%)$ & $816(43.1 \%)$ & 994 (52.5\%) \\
\hline Total & $267(14.1 \%)$ & 367 (19.4\%) & $121(6.4 \%)$ & 1138 (60.1\%) & $1893(100 \%)$ \\
\hline
\end{tabular}

Linear by linear association test for the trend: $p<0.001$

\section{Transition from one tobacco product to another}

Our results showed that, $8 \%$ of the male conscripts had quit smoking, and of these $35 \%$ used snus daily, $13 \%$ occasionally, and $20 \%$ had quitted the use of snus.

In total $6 \%$ of all participants had stopped using snus. Of these, $43 \%$ smoked daily, $13 \%$ occasionally, and $26 \%$ had quit smoking. Table 3.

\section{Additional analysis}

We studied the robustness of the results represented in the chapters above in respect to age distribution by excluding the older age groups from the analysis. Age groups 19 years and 19-21 years were analyzed separately. The results were coherent with the whole study material.

\section{Summary of key results}

Our results showed that one third of the participants reported snus usage, of which $42 \%$ used snus daily (i.e $14 \%$ of the study subjects). Smoking was also more common than expected. One fourth of the study population smoked daily, while as many as $40 \%$ reported sporadic or regular cigarette consumption. The dual use of cigarettes and snus was surprisingly high, with $21 \%$ of all conscripts reporting dual usage. Interestingly, about one third of former smokers reported daily snus usage and over $40 \%$ of reported quitters in the snus-using group smoked daily - showing a transition to another tobacco product instead of quitting.

Table 3 Transition from one tobacco product to another after quitting either smoking or snus use among young Finnish male conscripts

\begin{tabular}{lll}
\hline & $\begin{array}{l}\text { Former smokers } \\
(N=158)\end{array}$ & $\begin{array}{l}\text { Former snus users } \\
(N=121)\end{array}$ \\
& $\begin{array}{l}\text { Do you use } \\
\text { snus now? }\end{array}$ & $\begin{array}{l}\text { Do you currently } \\
\text { smoke? }\end{array}$ \\
\hline Daily & $56(35.4 \%)$ & $52(43.0 \%)$ \\
Occasionally & $20(12.7 \%)$ & $16(13.2 \%)$ \\
Used earlier, but have quitted & $31(19.6 \%)$ & $31(25.6 \%)$ \\
No transition to another & $51(32.3 \%)$ & $22(18.2 \%)$ \\
tobacco product after quitting & & \\
\hline Cf. Table 2 & &
\end{tabular}

\section{Discussion}

We analyzed the prevalence and dual use of cigarettes and snus, as well as transition from one tobacco product to another, among young male adults at the beginning of their military service. We found that dual consumption of cigarettes and snus was common, especially among daily smokers as many as half reported simultaneous snus usage. Interestingly, about one third of former smokers reported daily snus usage and over $40 \%$ of reported quitters in the snus-using group smoked daily - showing a transition to another tobacco product instead of quitting.

Limited data is available regarding dual use of cigarettes and snus or transition behavior, particularly in this target group. However, Scandinavian and Northern American studies imply that snus usage is growing among young adults. Dual usage is still uncommon and is mostly associated with current smoking. The prevalence of exclusive snus usage is high in Sweden and Norway where the trade of smokeless tobacco is legal [7, $18,20,43,44]$.

Our study results are in line with the study conducted on recruits in Northern Finland by Hamari et al.(2013) [8]. Furthermore, the School Health Promotion Study indicated that the dual use of cigarette and snus is currently gaining popularity among Finnish adolescents in their late teens [11]. Some dual users might be at a transitional stage, switching from one product to another, but it is noteworthy that the probability of continuing dual usage is high $[6,7,45]$.

We observed that the transition from one tobacco product to another among reported quitters was very common. About one third of former smokers reported daily snus usage. Over $40 \%$ of reported quitters in the snus-using group smoked daily instead. For a more accurate understanding of the phenomenon, it would have been valuable to determine the time elapsed in the transition, as well as the time-span after quitting smoking. Unfortunately, we did not collect this data. Based on our findings, the prevalence of both snus usage and smoking was significantly higher than in the Finnish national health surveys [11, 21, 24, 46]. Daily smoking was twice as common in our study and snus usage was three times more common than in the adolescent health and lifestyle survey $[21,24]$. On the other hand, the corresponding use 
of snus among Finnish army recruits in Northern Finland has been shown earlier. This trend is worrying considering that the trade of smokeless tobacco is banned in the European Union (excluding Sweden) and might reflect a wider international trend $[3,8,44]$. Finland's geographical vicinity to Sweden makes illegal trade compelling.

Large population-based health examination surveys provide a good overall understanding of the tobacco habits of adolescents and the adult population, although the response rates have decreased and rarely exceed $70 \%$. The exceptionally high response rate of over $97 \%$ gained in our study might explain the marked difference in the prevalence of smoking between studies.

Smoking was common among the study subjects with a basic educational background. The difference was clear compared to the study subjects with an upper secondary education, of whom only $10 \%$ smoked daily. Snus usage was equally common for all educational levels. Our results confirm previous findings associating lower educational status and smoking in Northern European countries [29]. However, we could not confirm any association between the level of education and snus use. This association has not been clear in earlier studies either, although some studies have shown a less prominent association among snus users $[19,47]$.

The strength of our study was the ability to carry it out in a military setting and to reach a comprehensive portion of young adult males, since all adult Finnish males are liable for military service. The survey was conducted upon arrival during the general health inspection, which motivated the conscripts to answer the questionnaire. The response rate was significantly higher than in most national surveys. Answering the survey was restricted to the first week of the military service to ensure responses that reflected the tobacco habits before the military culture had influenced them.

A common concern is selection bias. Young smoking men with a low education are typically under-represented $[24,46,48-50]$. A minority of young men are exempted from military service due to suitability or health issues, such as mental health problems, causing a possibility of bias in our results. We do not know the prevalence of tobacco use among these individuals, but we may assume that the prevalence of tobacco usage is likely to be even higher among the non-selected population. As for women, military service is voluntary and only a few women are recruited for service. We therefore excluded women from the results due to the low number of participants.

\section{Conclusions}

Our findings showed that exclusive snus use as well as dual usage of cigarettes and snus was significantly higher than expected from previous studies. A statistically significant correlation between educational level and exclusive snus usage could not be demonstrated.

This study provides a better understanding of the complex tobacco habits of young adult males, who are an important target population for health interventions. Young adults are at a transitional and vulnerable age when the usages of tobacco products, as well as other health habits, are yet to be established. The simultaneous usage of multiple tobacco products as well as the high tendency of transition from one tobacco product to another, should be taken into consideration when planning cessation interventions in health care settings and tobacco control policies at societal levels.

\section{Additional file}

Additional file 1: The questionnaire used to conduct the survey regarding the tobacco habits among conscripts. (DOCX $24 \mathrm{~kb}$ )

\section{Abbreviations}

WHO: World Health Organization; WMA: World Medical Association

\section{Acknowledgements}

We thank all the conscripts who participated in this survey and our dedicated team from The Guard Jaeger Regiment, the Karelian Brigade and the Kainuu Brigade who kindly helped us collect the data for this project. We also want to express our gratitude to Ph. D Clarissa Bingham for her valuable contribution regarding the set up of the study design and to Gareth Attwood and Patrik Silén for excellent language planning.

\section{Authors' contributions}

MD participated in designing the study, collected the clinical data, and was involved in analysing the data and writing the manuscript. TV participated in designing the study, was involved in analysing the data and writing the manuscript. LP was involved in analysing the data and writing the manuscript. JO participated in designing the study and performed the statistical analysis. SS participated in designing the study and writing the manuscript. AL participated in designing the study, was involved in analysing the data and writing the manuscript. All authors read and approved the final manuscript.

\section{Funding}

The research was financially supported by the Finnish Defence Forces and the Finnish Anti Tuberculosis Association Foundation. That funding was used for the analysis and writing by the first author, Maria Danielsson and for statistical analyses by the fourth author, Jukka Ollgren. The funding body was not involved in the design of the study or the interpretation of the data.

\section{Availability of data and materials}

The datasets generated and/or analysed during the current study are not publicly available due to unpublished material that will be used in future publications but are available from the corresponding author on reasonable request.

\section{Ethics approval and consent to participate}

The study protocol was approved by the Ethical Committee of the Hospital district of Helsinki and Uusimaa, Finland. (Number 148/13/03/00/2013). The Finnish Defence Forces granted permission to perform the study. Answering the survey was voluntary. Each recruit was first provided with written and verbal information on the survey, and there after they were asked to sign an informed consent form.

Consent for publication

Not applicable. 


\section{Competing interests}

Author Maria Danielsson has received research grants from The Finnish Defence Forces and from the Finnish Anti Tuberculosis Association Foundation.

Author Jukka Ollgren has received consultation fee regarding the statistics from The Finnish Defence Forces and the Finnish Lung Health Association. The other authors declare that they have no competing interest.

\section{Author details}

${ }^{1}$ The Finnish Defence Forces, Fabianinkatu 2, 00130 Helsinki, Finland. ${ }^{2}$ Doctoral School in Health Sciences, University of Helsinki, P.O. BOX 3, 00014 Helsinki, Finland. ${ }^{3}$ Finnish Lung Health Association (FILHA), Filha Ry, Sibeliuksen katu 11 A 1, 00250 Helsinki, Finland. ${ }^{4}$ National Institute for Health and Welfare, P.O. BOX 30, 00271 Helsinki, Finland. ${ }^{5}$ Finnish Medicine Agency Fimea, Helsinki, Finland. ${ }^{6}$ Division of Medicine, Department of Oncology, Turku University Hospital, and University of Turku, P.O. Box 52, 20521 Turku, Finland. ${ }^{7}$ Division of Medicine, Department of Pulmonary Diseases and Clinical Allergology, Turku University Hospital, and University of Turku, P.O. Box 52, 20521 Turku, Finland.

\section{Received: 5 February 2019 Accepted: 20 August 2019}

\section{Published online: 11 September 2019}

\section{References}

1. World Health Organization. WHO report on the global tobacco epidemic 2015; raising taxes on tobacco. Luxembourg: WHO; 2015. https://www.who. int/tobacco/global_report/2015/en/.

2. Wiium N, Aaro LE, Hetland J. Subjective attractiveness and perceived trendiness in smoking and snus use: a study among young Norwegians. Health Educ Res. 2009:24(1):162-72.

3. World Health Organization. Global report on trends in prevalence of tobacco smoking 2015. Geneva: World Health Organization; 2015. http:// apps.who.int/iris/bitstream/10665/156262/1/9789241564922_eng.pdf?ua=1.

4. Commission E. Revision of the Tobacco Products Directive 201816.4. Available from: https://ec.europa.eu/health/tobacco/products/revision_en.

5. Kalkhoran S, Grana RA, Neilands TB, Ling PM. Dual use of smokeless tobacco or e-cigarettes with cigarettes and cessation. Am J Health Behav. 2015;39(2): 277-84

6. Kaufman AR, Land S, Parascandola M, Augustson E, Backinger CL. Tobacco use transitions in the United States: the National Longitudinal Study of adolescent health. Prev Med. 2015;81:251-7.

7. Lund KE, McNeill A. Patterns of dual use of snus and cigarettes in a mature snus market. Nicotine Tob Res. 2013;15(3):678-84.

8. Hamari AK, Toljamo TI, Kinnula VL, Nieminen PA. Dual use of cigarettes and Swedish snuff (snus) among young adults in northern Finland. Eur J Pub Health. 2013:23(5):768-71.

9. Bombard JM, Pederson LL, Nelson DE, Malarcher AM. Are smokers only using cigarettes? Exploring current polytobacco use among an adult population. Addict Behav. 2007;32(10):2411-9.

10. Bombard JM, Rock VJ, Pederson LL, Asman KJ. Monitoring polytobacco use among adolescents: do cigarette smokers use other forms of tobacco? Nicotine Tob Res. 2008;10(11):1581-9.

11. Ollila H, Ruokolainen O. Tupakkatuotteiden yhteiskäyttö yläkouluissa ja toisen asteen oppilaitoksissa 2000-2015. Tutkimuksesta tiiviisti: 2016_002, THL; 2016.

12. Galanti MR, Rosendahl I, Wickholm S. The development of tobacco use in adolescence among "snus starters" and "cigarette starters": an analysis of the Swedish "BROMS" cohort. Nicotine Tob Res. 2008;10(2):315-23.

13. Furberg $H$, Lichtenstein P, Pedersen NL, Bulik C, Sullivan PF. Cigarettes and oral snuff use in Sweden: prevalence and transitions. Addiction. 2006; 101(10):1509-15.

14. Tomar SL. Snuff use and smoking in U.S. men: implications for harm reduction1. Am J Prev Med. 2002;23(3):143-9.

15. Haddock CK, Weg MV, DeBon M, Klesges RC, Talcott GW, Lando H, et al. Evidence that smokeless tobacco use is a gateway for smoking initiation in young adult males. Prev Med. 2001;32(3):262-7.

16. Gmel G, Clair C, Rougemont-Bücking A, Grazioli VS, Daeppen J-B, MohlerKuo M, et al. Snus and snuff use in Switzerland among young men: are there beneficial effects on smoking? Nicotine Tob Res. 2017;20:1301.

17. World Health Organization, International Agency for Research on Cancer. Smokeless tobacco and some tobacco-specific nitrosamines. (IARC)
Monographs on the evaluation of carcinogenic risk to humans. 89. Lyon. p. 88-143, 444-451. https://monographs.iarc.fr/wp-content/uploads/2018/06/ mono89.pdf.

18. Leon ME, Lugo A, Boffetta P, Gilmore A, Ross H, Schüz J, et al. Smokeless tobacco use in Sweden and other 17 European countries. Eur J Pub Health. 2016;26(5):817-21.

19. Engstrom K, Magnusson C, Galanti MR. Socio-demographic, lifestyle and health characteristics among snus users and dual tobacco users in Stockholm County, Sweden. BMC Public Health. 2010;10:619.

20. Tomar SL, Alpert HR, Connolly GN. Patterns of dual use of cigarettes and smokeless tobacco among US males: findings from national surveys. Tob Control. 2010;19(2):104-9.

21. Kinnunen JM, Ollila H, Pere LA, Lindfors PL, Rimpela AH. Nuorten terveystapatutkimus 2015, tupakkatuotteet ja päihteet 1977-2015. Sosiaalija terveysministeriö; 2015.

22. Mays D, Arrazola RA, Tworek C, Rolle IV, Neff LJ, Portnoy DB. Openness to using non-cigarette tobacco products among U.S. young adults. Am J Prev Med. 2016;50(4):528-34.

23. Choi K, Forster J. Awareness, perceptions and use of snus among young adults from the upper Midwest region of the USA. Tob Control. 2013;22(6):412-7.

24. Kinnunen JM, Pere LA, Raisamo S, Katainen A, Ollila H, Rimpela AH. The adolescent health and lifestyle survey 2017:adolescent smoking, alcohol use and gambling. Helsinki: Ministry of Social Affairs and Health; 2017. p. 108. http://urn.fi/URN:ISBN:978-952-00-3878-6.

25. Lund M, Lund KE, Halkjelsvik T. Contrasting smokers' and snus users' perceptions of personal tobacco behavior in Norway. Nicotine Tob Res. 2014;16(12):1577-85.

26. Fagerström KO, Schildt E-B. Should the European Union lift the ban on snus? Evidence from the Swedish experience. Addiction. 2003;98(9):1191-5.

27. Ramström LM, Foulds J. Role of snus in initiation and cessation of tobacco smoking in Sweden. Tob Control. 2006;15(3):210-4

28. Piano MR, Benowitz NL, FitzGerald GA, Corbridge S, Heath J, Hahn E, et al. Impact of smokeless tobacco products on cardiovascular disease: implications for policy, prevention, and treatment. Circulation. 2010;122(15): 1520-44.

29. Cavelaars AEJM, Kunst AE, Geurts JJM, Crialesi R, Grötvedt L, Helmert U, et al. Educational differences in smoking: international comparison. BMJ. 2000; 320(7242):1102-7.

30. Huisman M, Kunst AE, Mackenbach JP. Educational inequalities in smoking among men and women aged 16 years and older in 11 European countries. Tob Control. 2005;14(2):106-13.

31. Grotvedt L, Stigum H, Hovengen R, Graff-Iversen S. Social differences in smoking and snuff use among Norwegian adolescents: a population based survey. BMC Public Health. 2008;8:322

32. Higgins ST, Redner R, Priest JS, Bunn JY. Socioeconomic disadvantage and other risk factors for using higher-nicotine/tar-yield (regular full-flavor) cigarettes. Nicotine Tob Res. 2016;19:1425.

33. Wang Y, Sung H-Y, Yao T, Lightwood J, Max W. Factors associated with short-term transitions of non-daily smokers: socio-demographic characteristics and other tobacco product use. Addiction. 2016;112:n/a.

34. Conscription Act (1438/2007). Finnish Ministry of Justice, Finland. 2007. Available from: http://www.finlex.fi/en/laki/kaannokset/2007/en2007143 8?search\%5Btype\%5D=pika \& search\%5Bpika\%5D=conscript. Cited 18.4. 2018

35. Act on the Defence Forces. Ministry of Defence, Finland. 2008. Available from: http://www.finlex.fi/fi/laki/kaannokset/2007/en20070551.pdf. Cited 18.4.2018.

36. The Finnish Defence Forces. Conscription: the Finnish Defence forces; 2017 Available from: http://puolustusvoimat.fi/en/conscription.

37. Laki naisten vapaaehtoisesta asepalveluksesta. Ministry of Justice, Finland. 1995. Available from: http://www.finlex.fi/fi/laki/ajantasa/1995/19950194? search\%5Btype\%5D=pika \& search\%5Bpika\%5D=naisten\%20asepalvelus. Cited 16.4.2018

38. Siilasmaa R, Ahtisaari M, Ala-Pietila P, Komi K, Ojajärvi A. Suomalainen asevelvollisuus. Ministry of Defence, Finland; 2010.

39. Se H. Methodology report, Health 2000 Survey. Helsinki, Finland Capacity DoHaF: Publications of the National Public Health Institute; 2008.

40. McNemar Q. Note on the sampling error of the difference between correlated proportions or percentages. Psychometrika. 1947;12(2):153-7.

41. Agresti A. Categorical data analysis. Gainesville: Wiley; 2002.

42. Amrhein V, Greenland S, McShane B. Retire statistical significance. Nature. 2019;567:305-7. 
43. Cheng YC, Rostron BL, Day HR, Stanton CA, Hull LC, Persoskie A, et al. Patterns of use of smokeless tobacco in US adults, 2013-2014. Am J Public Health. 2017;107(9):1508-14.

44. Tam J, Day HR, Rostron BL, Apelberg BJ. A systematic review of transitions between cigarette and smokeless tobacco product use in the United States. BMC Public Health. 2015;15:258.

45. Mejia $A B$, Ling PM, Glantz SA. Quantifying the effects of promoting smokeless tobacco as a harm reduction strategy in the USA. Tob Control. 2010;19(4):297-305.

46. Helldán A, Helakorpi S. Health behaviour and health among the Finnish adult population. Helsinki: National Institute for Health and Welfare; 2015. https://thl.fi/fi/tutkimus-ja-asiantuntijatyo/vaestotutkimukset/aikuistenterveys-hyvinvointi-ja-palvelututkimus-ath/aiemmat-tutkimukset/ suomalaisen-aikuisvaeston-terveyskayttaytyminen-ja-terveys-avtk.

47. Tanner T, Kämppi A, Päkkilä J, Järvelin M-R, Patinen P, Tjäderhane L, et al. Association of smoking and snuffing with dental caries occurrence in a young male population in Finland: a cross-sectional study. Acta Odontol Scand. 2014;72(8):1017-24.

48. Helakorpi S, Makela P, Holstila A, Uutela A, Vartiainen E. Can the accuracy of health behaviour surveys be improved by non-response follow-ups? Eur J Pub Health. 2015;25(3):487-90.

49. Reinikainen J, Tolonen H, Borodulin K, Harkanen T, Jousilahti P, Karvanen J, et al. Participation rates by educational levels have diverged during 25 years in Finnish health examination surveys. Eur J Pub Health. 2018;28(2):237-43.

50. Mindell JS, Giampaoli S, Goesswald A, Kamtsiuris P, Mann C, Männistö S, et al. Sample selection, recruitment and participation rates in health examination surveys in Europe - experience from seven national surveys. BMC Med Res Methodol. 2015;15:78.

\section{Publisher's Note}

Springer Nature remains neutral with regard to jurisdictional claims in published maps and institutional affiliations.

Ready to submit your research? Choose BMC and benefit from:

- fast, convenient online submission

- thorough peer review by experienced researchers in your field

- rapid publication on acceptance

- support for research data, including large and complex data types

- gold Open Access which fosters wider collaboration and increased citations

- maximum visibility for your research: over $100 \mathrm{M}$ website views per year

At $\mathrm{BMC}$, research is always in progress.

Learn more biomedcentral.com/submissions 